\title{
EXTENT OF SIGHT DISTANCE REDUCTIONS CAUSED BY RAINFALL ON SINGLE CARRIAGEWAY ROADS
}

\author{
Johnnie Ben-Edigbe', Nordiana Mashros ${ }^{2}$, Raha Rahman ${ }^{3}$ \\ 1,2,3 Department of Geotechnics and Transportation, Universiti Teknologi, Malaysia
}

Received 9 December 2012; accepted 12 April 2013

\begin{abstract}
The paper is aimed at probing the extent of sight distance reductions along a single carriageway road caused rainy conditions. Stopping and passing sight distances were investigated under dry weather, light, moderate and heavy rainy condition. Rainfall intensities being; light $<2.5 \mathrm{~mm} / \mathrm{h}$, moderate $2.5-10 \mathrm{~mm} / \mathrm{h}$ and heavy $10-50 \mathrm{~mm} / \mathrm{h}$ were based on Malaysian meteorology classification system. Based on the hypothesis that rainfall irrespective of intensity has significant effect on roadway visibility and by extension sight distance reductions, impact studies were carried out at two locations at Terengganu, Malaysia. Continuous traffic volume, speed, vehicle types and headway data were collected for 8 weeks, collated and analysed. Results show about $17 \%$ reduction in average stopping and passing sight distances due to rainfall. The paper concluded that irrespective of their intensities rainfalls have significant impact on sight distances.
\end{abstract}

Keywords: critical passing sight distance, probability function, rainfall.

\section{Introduction}

Rainfall causes the most dramatic impact on traffic flow due to its spatiotemporal nature. Therefore it's not unusual for driver to become agitated before, at the onset, during and even after any rainfall. It's a global phenomenon. The principal problems of rainfall for road traffic are poor visibility and aquaplaning. Both would exacerbate traffic stream operation. The impact of these disturbances to the traffic stream is such that the sight distances of the highway are reduced, relative travel time is lost and the risk of crash increases. Previous studies have shown that motorists adjust their behaviour during rainfall (Alhassan and Ben-Edigbe, 2011). According to Mohan Rao and Ramachandra Rao (2012) capacity is one of the most important elements of road space supply.
When capacity is compromised, motorists will experience increase in travel time. They overtake less, drive slower and increase their following distance. Consequently, the extent of sight distance reduction is the focus of this paper.

Stopping and passing sight distances are important traffic safety indicator especially on single carriageway roads, but then how would sight distances be affected by rainfall intensities, it may be queried? Stopping sight distance (SSD) is the required distance that a driver needs to see in order to avoid colliding with object ahead on the roadway. SSD design values used in Malaysia manual often represent the worst case scenarios and are made up of two important components; reaction and braking distances. Both are treated as one entity.

${ }^{1}$ Corresponding author: edigbe@utm.my 
The extent to which rainy conditions on a single carriageway would bear on the SSD values has yet to be studied in unison with passing sight distance. Unlike SSD, passing sight distance (PSD) has not been studied that much if all and where it has been studies, the outcomes have not been compared those of stopping sight distance. Passing sight distance is restricted to single carriageway road and is often taken as the length of highway required by a driver to make a passing maneuver without cutting off the passed vehicle and before meeting an opposing vehicle. The most important commonality between SSD and PSD is visibility. Reduced visibility means heightened probability of collusion. The presence of poor visibility occasioned by rainfall, poor or no road lighting, and poor surface friction is avoidable on the single carriageway given proper and adequate design with consideration for safety. However, it is equally important to bear in mind that the decision to undertake passing maneuver is entirely that of the driver irrespective of design and prevailing conditions and consequences are often after thoughts. Some drivers approach passing maneuver responsibly while others are reckless, in the paper, $85^{\text {th }}$ percentile of observed speeds are taken into consideration.

In Malaysia, rainfall is high, regular and fairly uniform. There are only few areas in Malaysia with less than $2540 \mathrm{~mm}$ of rain per year. However, there are also marked differences in the average annual totals between different parts of the country. The highlands of Sabah and Sarawak receive more than $4064 \mathrm{~mm}$ per year and large areas have in excess of $2540 \mathrm{~mm}$ per year. Areas in northern Kedah and Perlis and in Southern Pahang can receive less than $1524 \mathrm{~mm}$ per annum. Most parts of Malaysia receive rainfall peaks during the time of the north-east monsoon, i.e. from November to
February when rainfalls of $150 \mathrm{~mm}$ per day are common in most areas. The east coast of the Peninsula and Sabah and Sarawak receive up to $40 \%$ of their annual rainfall at this time. In the period from May to September, south-west or southerly air streams dominate Malaysia. This is a relatively dry period except for the south-west Malaysian Peninsula.

Based on the hypothesis that rainfall irrespective of intensity has significant effect on roadway visibility and by extension sight distance reductions the remainder of the paper has been dived into four sections. The immediate section is on literature review while in section 3 , setup of impact study and data collection are discussed. In section 4, collected data are analysed and their findings presented. In section 5 , conclusions are drawn.

\section{Literature Review on Sight Distance Concepts}

Rainfall intensity is often taken as the amount of rainfall that fall per unit time and by far rainfall the most likely meteorological phenomenon that could affect an otherwise reasonable traffic stream characteristics (Hogema, 1996). It is usually measured in millimetres per hour or millimetres per day using a rain gauge. High resolution rainfall data such as millimetres in say $1 \mathrm{~min}, 2 \mathrm{~min}, 5 \mathrm{~min}$ and $10 \mathrm{~min}$ are possible with modern equipment such as data loggers. Rain drops sizes are probably associated with rainfall intensity. Bigger rain drop sizes resulting in higher rainfall intensities. The problem of sight distance reduction on highways during rainfall could be linked to larger sizes of rain drops falling and thereby blurring the vision of drivers. Rainfalls of low intensity tend to be associated with smaller spherical rain drops and their sizes range from 0.1 millimetres to 9 millimetres mean diameter, above which they tend to break up (Keay and Simmonds, 2005). 
Rainfall intensity is classified as light $<2.5$ $\mathrm{mm} / \mathrm{h}$, moderate $2.5-10 \mathrm{~mm} / \mathrm{h}$ and heavy $10-50$ $\mathrm{mm} / \mathrm{h}$ (Alhassan and Ben-Edigbe, 2011). Each level of rainfall intensity could be associated with blur vision as well as a drop in the speed profile of the traffic stream. If the relationship between speed drop and rainfall intensity could be established, it will be possible to speculate on the possible traffic flow scenario that will emerge during rainfall and the intervention measures required. Notwithstanding, it can be postulated that since minimum sight distances are mandated in Malaysia design guidelines, whether it rains or not, fixed minimum sight distances are component part of the road infrastructure. As illustrated in Fig. 1 below, fixed minimum sight distances $\left(D_{f}\right)$ is the threshold for traffic safety, should rainfall induce sight distance reduction below the fixed minimum sight distances, then the probability of collision would be enhanced. The variable sight distances $\left(D_{y}\right)$ is discretional shown in Fig. 1 has linear relationship with rainfall intensity. So, it can be postulated that increase in rainfall intensity may induce relative decrease in sight distance (Alhassan and Ben-Edigbe, 2011). It can be argued (Eq. (1) and Eq. (4)). According to Gurupackiam and Lee Jones Jr. (2012), lane changing refers to drivers changing roadway lanes without interfering with vehicles in the destination lane. Gap acceptance is the minimum size of gap in traffic flow that drivers are willing to accept while changing lanes. Consequently, gap acceptance and lane changing parameters have direct implications for sight distance.

\subsection{Stopping Sight Distance}

Stopping sight distance (SSD) is the length of roadway that should be visible to ensure that a

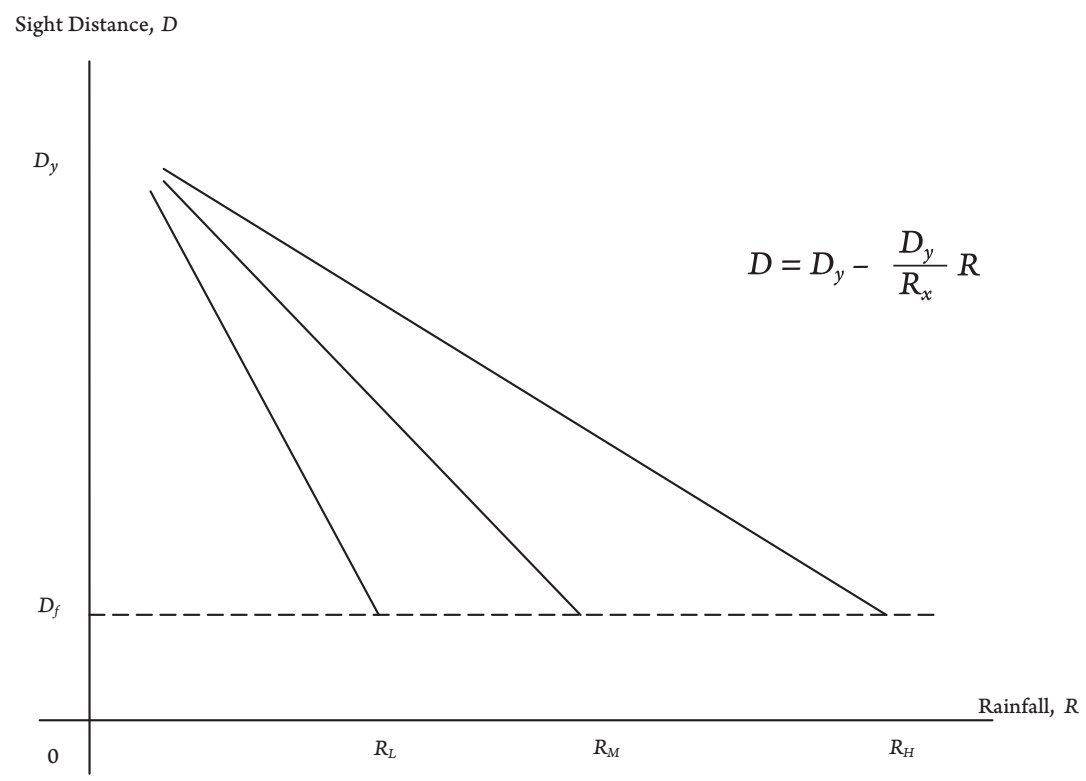

\section{Fig. 1.}

Hypothetical Sight Distance and Rainfall Relationship

Source: Ben-Edigbe, J. 
driver does not hit an object on his/her path. It is made up of two component paths; reaction and braking distance. It can be asserted that drivers will reduce their approach speed instinctively if visibility is blurred irrespective of how it happened. Since the studies were carried out on straight road segment, the basic principle of uniform velocity can be applied and the equations for uniform acceleration used. Three uniform acceleration equations are useful:

$v=u+a t$

$s=u t+\frac{a t^{2}}{2}$

$v^{2}=u^{2}+2 a s$

Where; $v$ is final velocity, $u$ is initial velocity, $t$ is time and $s$ is distance covered during acceleration.

For any traffic stream three parameters are important; flow, speed and density (Minderhoud et al., 1997; Yeon et al., 2009; Ben-Edigbe and Ferguson, 2005). These parameters are also related where:

$q=v k \Rightarrow v=\frac{q}{k}$

In theory, speed and density relationship has been used to compute empirical traffic speed. It follows that:

$v=v_{f}-\lambda k$

The reaction distance is tied to the amount of time that elapses between the recognition of perceived hazard in the roadway and application of brakes. It can be written as Eq. (7):

$d_{R}=0.278 v t$
Where $t=$ reaction time $(1.5 \mathrm{~s}-2.5 \mathrm{~s})$ and $v=$ mean speed. If it is postulated that empirical gap $(g)$ time is more indicative of reaction time than, $t=$ reaction time $(1.5 \mathrm{~s}-2.5 \mathrm{~s})$, and empirical gap is a function of headway then gap can be written as Eq. (8):

$g=\left\{\left(\frac{3600}{q_{m}}\right)+\left(\frac{L}{v}\right)\right\}$

Where headway, $h=3600 / q$, $L$ is the average length of vehicles in the traffic stream, $q_{m}$ denotes empirical maximum traffic flow rate. If Eq. (8) is plugged into Eq. (7), then reaction distance can be rewritten as Eq. (9):

$d_{R}=0.278 v\left\{\left(\frac{3600}{q_{m}}\right)+\left(\frac{L}{v}\right)\right\}$

The braking distance on the other hand is the distance that a vehicle travels while slowing to a complete stop and it can be written as Eq. (10):

$d_{B}=\frac{0.039 v^{2}}{\alpha}$

Where $a$ denotes deceleration rate.

Since SSD is a summation of $d_{R}$ and $d_{B}$, it can be written as Eq. (11):

$D_{s}=\left\{\left[0.278 v\left(\left(\frac{3600}{q_{m}}\right)+\left(\frac{L}{v}\right)\right)\right]+\left(\frac{0.039 v^{2}}{\alpha}\right)\right\}(11)$

\subsection{Passing Sight Distance}

Passing sight distance (PSD) is the sight distance required by a passing vehicle or driver to safely initiate and complete a passing manoeuvre. To overtake another vehicle safely on two-lane highways, a driver must consider the relative speeds and positions of the driver's own vehicle, the vehicle to be overtaken and 
oncoming vehicle in the opposite direction. As shown in Fig. 2, passing manoeuvre involves four elements:

$d_{1}=$ distance the passing vehicle travels while contemplating the passing manoeuvre;

$d_{2}=$ length of roadway that is traversed by the passing vehicle while it occupies the right lane;

$d_{3}=$ clearance distance between the passing vehicle and the opposing vehicle;

$d_{4}=$ distance that the opposing vehicle travels.

Passing sight distance (PSD) is a critical component of single carriageway road infrastructure design; proving a sufficient passing sight distance is expensive even though the road capacity is enhanced if a large part of the road can be used for this manoeuvre. As contained in Malaysian Highway Capacity Manual (MHCM, 2011), the minimum passing sight distance on a single carriageway with 80 $\mathrm{km} / \mathrm{h}$ design speed is $550 \mathrm{~m}$. The minimum PSD as the sum of the following four distances and it can be written as Eq. (12):

$$
D_{p}=d_{1}+d_{2}+d_{3}+d_{4}
$$

As contained in many literatures, $d_{3}=0.2 d_{4}$ and $d_{4}=2 d_{2} / 3$.

However, the distance traveled during the initial maneuver period is (Eq. (13)):

$$
d_{1}=0.278 t_{1}\left(v-m+\frac{\alpha t_{1}}{2}\right)
$$

Where:

$t_{1}=$ time of initial maneuver, $\mathrm{s}$;

$a=$ average acceleration, $\mathrm{km} / \mathrm{h} / \mathrm{s}$;

$v=$ average speed of passing vehicle, $\mathrm{km} / \mathrm{h}$; and

$m=$ difference in speed of passed vehicle and passing vehicle.

Let the cruising speed before overtaking $v$; the overtaking speed be $\mu$; and acceleration rate be $a$ so that,

$t_{2}^{\alpha}=\frac{u-v}{\alpha}$

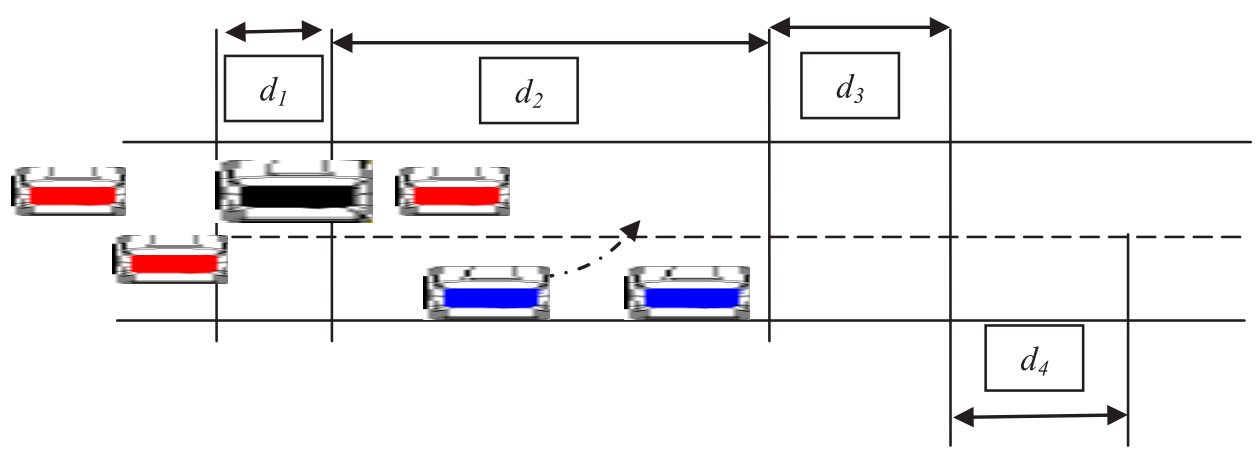

Fig. 2.

Typical Illustration of Passing Sight Distance Components

Source: Ben-Edigbe, J. 
Where,

$\alpha=\lim _{\partial t \rightarrow 0}\left(\frac{\partial v}{d t}\right)$

Distance traveled due to acceleration,

$D_{2}^{\alpha}=v t_{2}^{\alpha}+\frac{1}{2} \alpha\left(t_{2}^{\alpha}\right)^{2}$

Distance covered by vehicle/s being overtaken during overtaking,

$D_{o}=0.278 v t_{2}^{\alpha}$

Total Distance needed for overtaking,

$D_{T}=C_{1}+L+C_{2}$

Where; $C$ denotes clearance and $L$ is vehicle/s length.
Distance Net gain,

$Z=D_{T}-\left(D_{2}^{\alpha}-D_{o}\right)$

Hence; time passing vehicle occupies the right lane;

$t_{2}=\frac{Z}{(u-v)}$

The distance traveled by the passing vehicle while occupying the right lane is estimated as Eq. (15):

$d_{2}=0.278 v t_{2}$

Where;

- $t_{2}$ denotes time passing vehicle occupies the right lane, and

$-v$ denotes average speed of passing vehicle, $\mathrm{km} / \mathrm{h}$.

Passing sight distance,

$D_{p}=\left\{\left[0.278 t_{1}\left(v-m+\frac{\alpha t_{1}}{2}\right)\right]+0.278 v t_{2}+0.2 d_{4}+\frac{2 d_{2}}{3}\right\}$

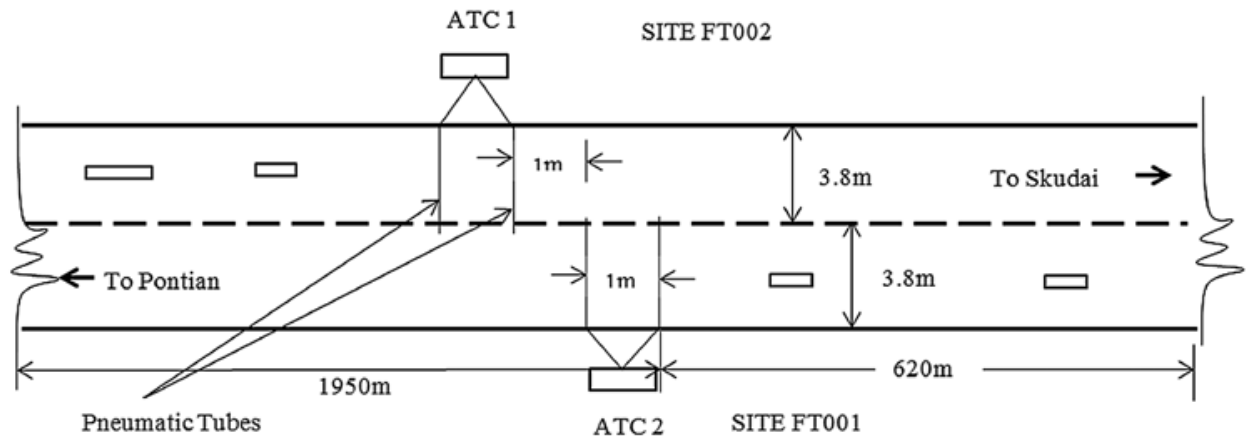

Note: ATC denotes Automatic Traffic Counter.

Fig. 3.

Layout of Typical Survey Sites

Source: Ben-Edigbe, J. 


\section{Data Collection}

In order to be able to determine impact of rainfall on sight distance a 'with and without rainfall impact study' was carried out on a single carriageway road section in Skudai town, Malaysia. The layout of study sites is illustrated in Fig. 3.

Data were collected during the rainy season. The selected section has straight and flat road, good road surfaces and effective drain system. Traffic flows at the study sites were not influenced by factors such as petrol stations, bus stations, mosques, entry to villages, traffic signals, crossroads, and also side parking. An automatic traffic counter was installed on the road section to collect traffic data. Detail individual vehicles information were recorded: date, time, speed, direction of travel, headway, gap, length of wheelbase, number of axles and vehicle classification when they traversed the observation point. Rainfall intensity data in 5 minutes intervals with date and time were obtained from the nearest rain gauge station belongs to Drainage and Irrigation Department, located approximately $1.8 \mathrm{~km}$ was coupled with the traffic data in order to identify traffic data during dry and rainfall conditions. Since

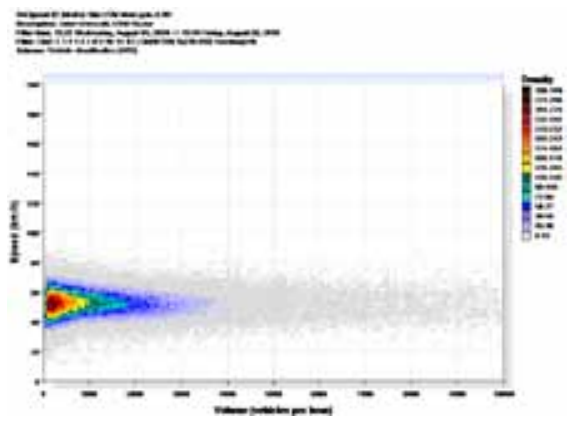

Fig. 4a. rainfall has different intensity, these data were further processed to categorize the traffic into three rainfall intensity groups: $R_{L} ; R_{M}$ and $R_{H}$. These are light rain, moderate rain and heavy rain. Rainfall in a very heavy group was not observed throughout the data collection period. The rainfall classification was based on the World Meteorological Organization (WMO) Scheme. In a month of December 2010, 41748 vehicles were recorded and the composition of traffic stream consist of $94.24 \%$ light goods vehicles, $2.71 \%$ medium goods vehicles and $3.05 \%$ were heavy goods vehicles.

\section{Results and Findings}

For any given highway traffic stream flow would be at capacity, free-flow or congestion. Since the study is interested in the impact of rainfall on sight distances, then traffic flows at congestion and capacity are excluded in the analysis in order to minimise their influence on speed. For the purpose of clarity, a stepwise analytical procedure has been adopted in this section.

Step 1 Traffic volume and speed scatter plots shown below in Fig. 4 were filtered and analysed.

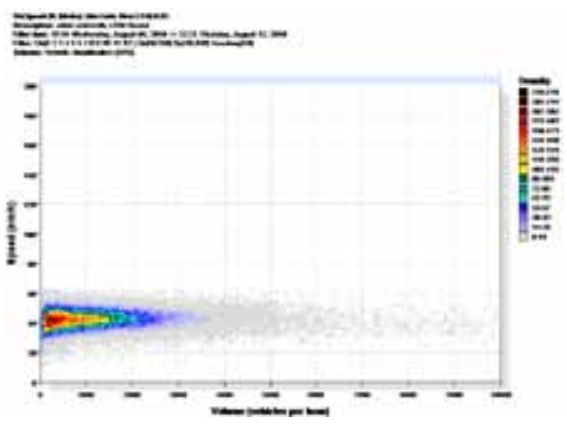

Fig. 4b.

Typical Site Speed-Volume Scatter Plot for Road Section without (a) and with Rainfall (b) Source: Ben-Edigbe, J. 
Step 2 Rainfalls were divided into three categories: light rain (LR) $(i<2.5 \mathrm{~mm} / \mathrm{h})$, moderate rain $(\mathrm{MR})(2.5 \leq i<10.0 \mathrm{~mm} / \mathrm{h})$ and heavy rain (HR) $(10.0 \leq i<50.0 \mathrm{~mm} / \mathrm{h})$.

Step 3 Traffic volume and speed data were separated into peak and off-peak periods. Traffic volumes were converted into flows using the appropriate passenger car equivalent values. The peak period data were then employed as control traffic stream data in order to make sure that computed traffic flows occurred at off-peak periods. Consequently, traffic volume was converted into flow and divided by speed to get density. The relationship between speed and density is such that as density increases speed decreases and it can be written as Eq. (17):

$u_{s}=u_{f}-\frac{u_{f}}{k_{j}} k$

Where; $u_{s}$ is the space mean speed, $u_{f}$ is free flow speed, $k$ is the density and $k_{j}$ is the density at jam. Given that highway traffic flow $(q)$, speed $(u)$ and density $(k)$ relationship can be used and written as Eq. (18):

$q=u k \Rightarrow u=\frac{q}{k} \Rightarrow k=\frac{q}{u}$

It follows that, if Eq. (17) is plugged into Eq. (18), the flow-density function can be written as Eq. (19):

$$
q_{m}=-c+a k-b k^{2}
$$

Where $q_{m}$ denoted maximum flow. The draw back with flow-density estimation method lies with determining the critical density. Since our interest is in estimating maximum flow, the choice of precise value of critical density need not be very critical to the outcome of this study. By computing maximum flow for each road segment, it is recognized that capacity varies per road section. Dry weather capacity for the road segment under observation was estimated by relating flow to density as illustrated below (Eq. (20)):

$$
q=-1.96+84.9 k-0.67 k^{2} R^{2}=0.95
$$

For maximum flow; $\partial q / \partial \kappa=2(-0.67 k)+$ $84.9=0$; Critical density, $k_{c} \cong 63.4 \mathrm{veh} / \mathrm{km}$,

Then plug $k_{c}$ into Eq. (20) so that $q=$ $-0.67(63.4)^{2}+84.9(63.4)-1.96$ and Capacity, $Q=2688 \mathrm{pce} / \mathrm{hr}$.

Step 4 Now that the control capacity has been estimated, observed and predicted traffic stream parameters can now be determined for dry and rainy conditions. Predicted traffic stream parameters were tested statistically for validity. All the coefficients of determination are above $50 \%$, suggesting that the ensuing model equation can be relied upon for predictions. Student t-test outcomes are above the 1.95 threshold at $85 \%$ confidence interval suggesting that the individual parameters used are significant, and the F-test results confirmed that the model equations did not happen by chance.

Step 5 Use Eq. (11) to determine stopping sight distance for sites 1 and 2 as shown below in Table 1. Note that all the traffic flows and their relative densities are well below the capacity threshold of $2688 \mathrm{pce} / \mathrm{h}$ and their corresponding critical density of 63 vehicles per kilometer. It confirms that the traffic stream is truly operating under free-flow condition; further that disturbance to the traffic flow can only be induced by rainfalls irrespective of their intensities. Note also that gap times were used instead of human reaction times. The reason for that is very simple; follow up vehicles reaction to gap between the 
vehicles not human reaction times. It's always advisable for motorists to keep a clearance distance that is greater that reaction time of $2 \mathrm{~s}$ or more so that in circumstance where they have to react to abnormal or abrupt stopping of lead vehicle they may avoid collisions. Speed $(v)$ reductions of about $15 \%$ due to rainfall at sites 1 and 2 are significant. Note that gap time increases relative to decrease in flow $(q)$, consequently relative headways are also increased. SSD for dry weather at site 1 was reduced $162 \mathrm{~m}$ to $124 \mathrm{~m}, 119 \mathrm{~m}$ and $109 \mathrm{~m}$ for light, moderate and heavy rainfall respectively; and for site 2 the reduction was from $178 \mathrm{~m}$ to $147 \mathrm{~m}, 135 \mathrm{~m}$ and $120 \mathrm{~m}$ for light, moderate and heavy rainfall respectively. Hypothesis was made to test the significance of SSD reduction as shown in Table 2; results suggest that SSD for dry weather differ significantly from SSD for light, moderate and heavy rainfall.

Step 6 Use Eq. (20) to determine passing sight distance for sites 1 and 2 as shown in
Table 2. Note that all the traffic flows and their relative densities are well below the capacity threshold of $2688 \mathrm{pce} / \mathrm{h}$ and their corresponding critical density of 63 vehicles per kilometer. It affirms that the traffic stream is truly operating under free-flow conditions; further that disturbance to the traffic flow can only be induced by rainfalls irrespective of their intensities. Speed $(v)$ reductions of about $15 \%$ due to rainfall at sites 1 and 2 are significant. Distance the passing vehicle travels while contemplating the passing manoeuvre $\left(d_{1}\right)$ decreases from $30 \mathrm{~m}$ for dry weather to $27 \mathrm{~m}, 28 \mathrm{~m}$ and $27 \mathrm{~m}$ at sites 1 ; from $42 \mathrm{~m}$ to $40 \mathrm{~m}, 37 \mathrm{~m}$ and $34 \mathrm{~m}$ at site 2 for light, moderate and heavy rainfall respectively. Length of roadway that is traversed by the passing vehicle while it occupies the right lane $\left(d_{2}\right)$ decreased from $262 \mathrm{~m}$ to $202 \mathrm{~m}$ at site 1 ; and also from $265 \mathrm{~m}$ to $205 \mathrm{~m}$ at site 2 . Clearance distance between the passing vehicle and the opposing vehicle $\left(d_{3}\right)$ decreased from $35 \mathrm{~m}$ to $27 \mathrm{~m}$ at site 1 ; and from $35 \mathrm{~m}$ to $27 \mathrm{~m}$ at site 2. Distance that the opposing vehicle travels

\section{Table 1}

Estimated SSD for Dry and Variable Rainy Conditions

\begin{tabular}{|c|c|c|c|c|c|c|c|c|c|c|c|}
\hline SITE & $P C$ & $\begin{array}{c}v \\
\mathrm{~km} / \mathrm{h} \\
\pm 8 \mathrm{~km} / \mathrm{h}\end{array}$ & $\begin{array}{c}q \\
\text { pce } / \mathbf{h}\end{array}$ & $\begin{array}{c}k \\
\text { veh } / \mathbf{k m}\end{array}$ & $\begin{array}{c}\boldsymbol{h}_{w} \\
\mathbf{s}\end{array}$ & $\begin{array}{c}\text { gap } \\
\mathbf{s}\end{array}$ & $\begin{array}{c}D_{R} \\
\text { m }\end{array}$ & $\begin{array}{c}D_{B} \\
\mathbf{m}\end{array}$ & $\begin{array}{c}D_{s} \\
\mathbf{m}\end{array}$ & $\begin{array}{c}\Delta D_{s} \\
\%\end{array}$ & $\mathrm{Cal} \chi^{2}$ \\
\hline \multirow{4}{*}{1} & Dry & 88 & 2115 & 24.0 & 1.702 & 1.477 & 36.14 & 125.8 & 162.0 & $\mathbf{n} / \mathbf{a}$ & $\mathrm{n} / \mathrm{a}$ \\
\hline & $L_{R}$ & 75 & 1954 & 26.1 & 1.842 & 1.579 & 32.91 & 91.4 & 124.3 & 15.4 & 8.91 \\
\hline & $M_{R}$ & 72 & 1779 & 24.7 & 2.024 & 1.749 & 35.00 & 84.2 & 119.2 & 17.0 & 11.41 \\
\hline & $H_{R}$ & 68 & 1709 & 25.1 & 2.106 & 1.816 & 34.32 & 75.1 & 109.5 & 17.9 & 17.34 \\
\hline \multirow{4}{*}{2} & Dry & 89 & 1624 & 18.2 & 2.217 & 1.994 & 49.35 & 128.7 & 178.1 & $\mathbf{n} / \mathbf{a}$ & $\mathrm{n} / \mathbf{a}$ \\
\hline & $L_{R}$ & 78 & 1448 & 18.6 & 2.486 & 2.233 & 48.41 & 98.9 & 147.3 & 11.5 & 5.39 \\
\hline & $M_{R}$ & 74 & 1441 & 19.5 & 2.498 & 2.231 & 45.89 & 89.0 & 134.9 & 13.6 & 10.38 \\
\hline & $H_{R}$ & 69 & 1427 & 20.7 & 2.523 & 2.236 & 42.89 & 77.4 & 120.3 & 23.7 & 18.89 \\
\hline
\end{tabular}

Source: Ben-Edigbe, J.

Note: $P C$-prevailing conditions; $h w$-headway; $g$-gap; $D_{R}$-reaction distance, $D_{B}$-braking distance, $v$-speed; $q$-flow

$L_{R}$-light rainfall; $M_{R}$-moderate rainfall; $H_{R}$-heavy rainfall; Recommended Minimum SSD $=130 \mathrm{~m}$ $\mathrm{Tab} \chi^{2}=3.14$ at $85 \mathrm{CI} .-\mathrm{H}_{0}: \mathrm{SSD}_{\text {without rainfall }}=\mathrm{SSD}_{\text {with rainfall }} ; \mathrm{H}_{1}: \mathrm{SSD}_{\text {without rainfall }} \neq \mathrm{SSD}_{\text {with rainfall }}$ 
Table 2

Estimated PSD for Dry and Variable Rainy Conditions

\begin{tabular}{|c|c|c|c|c|c|c|c|c|c|c|}
\hline SITE & $P C$ & $\begin{array}{c}v \\
\mathrm{~km} / \mathrm{h} \\
\pm 8 \mathrm{~km} / \mathrm{h}\end{array}$ & $\begin{array}{c}t_{1}=g \\
\mathrm{~s}\end{array}$ & $\begin{array}{l}d_{1} \\
\text { m }\end{array}$ & $\begin{array}{l}d_{2} \\
\mathbf{m}\end{array}$ & $\begin{array}{l}d_{3} \\
\mathbf{m}\end{array}$ & $\begin{array}{l}d_{4} \\
\text { m }\end{array}$ & $\begin{array}{c}D_{P} \\
\mathbf{m}\end{array}$ & $\begin{array}{c}\Delta D_{P} \\
\%\end{array}$ & $\begin{array}{c}\mathrm{Cal} \\
\chi^{2}\end{array}$ \\
\hline \multirow{4}{*}{1} & Dry & 88 & 1.477 & 30.3 & 261.8 & 34.9 & 174.5 & 501.5 & $\mathrm{n} / \mathrm{a}$ & $\mathbf{n} / \mathbf{a}$ \\
\hline & $L_{R}$ & 75 & 1.579 & 26.7 & 223.1 & 29.7 & 148.7 & 428.3 & 14.60 & 6.69 \\
\hline & $M_{R}$ & 72 & 1.749 & 28.2 & 214.2 & 28.6 & 142.8 & 413.7 & 17.50 & 10.39 \\
\hline & $H_{R}$ & 68 & 1.816 & 27.3 & 202.3 & 27.0 & 134.8 & 391.4 & 21.95 & 18.22 \\
\hline \multirow{4}{*}{2} & Dry & 89 & 1.994 & 41.8 & 264.7 & 35.3 & 176.5 & 518.3 & $\mathrm{n} / \mathrm{a}$ & $\mathrm{n} / \mathrm{a}$ \\
\hline & $L_{R}$ & 78 & 2.233 & 40.1 & 232.0 & 30.9 & 154.7 & 457.8 & 11.68 & $1.50^{*}$ \\
\hline & $M_{R}$ & 74 & 2.231 & 37.6 & 220.1 & 29.3 & 146.7 & 433.8 & 16.30 & 5.36 \\
\hline & $H_{R}$ & 69 & 2.236 & 34.6 & 205.2 & 27.4 & 136.8 & 404.0 & 22.05 & 13.53 \\
\hline
\end{tabular}

Source: Ben-Edigbe, J.

Note: $g=t_{2}=10.7 \mathrm{~s} ; a=2.37 \mathrm{~km} / \mathrm{h} / \mathrm{s} ; m=16 \mathrm{~km} / \mathrm{h}$; Minimum PSD for $70 \mathrm{~km} / \mathrm{h}=485 \mathrm{~m}$; $80 \mathrm{~km} / \mathrm{h}=500 \mathrm{~m}$

Tab $\chi^{2}=3.14$ at $85 C I .-\mathrm{H}_{0}: \mathrm{PSD}_{\text {without rainfall }}=\mathrm{PSD}_{\text {with rainfall }} ; \mathrm{H}_{1}: \mathrm{PSD}_{\text {without rainfall }} \neq \mathrm{PSD}_{\text {with rainfall }}$; *Accept $\mathrm{H}_{0}$

$\left(d_{4}\right)$ decreased from $174 \mathrm{~m}$ to $135 \mathrm{~m}$ at site 1 ; from $176 \mathrm{~m}$ to $137 \mathrm{~m}$ at site 2 . PSD for dry weather at site 1 was reduced $501 \mathrm{~m}$ to $428 \mathrm{~m}, 414 \mathrm{~m}$ and $391 \mathrm{~m}$ for light, moderate and heavy rainfall respectively; and for site 2 the reduction was from $518 \mathrm{~m}$ to $458 \mathrm{~m}, 434$ $\mathrm{m}$ and $404 \mathrm{~m}$ for light, moderate and heavy rainfall respectively. Hypothesis was made to test the significance of SSD reduction as shown in Table 2; results suggest that PSD for dry weather differ significantly from PSD for light, moderate and heavy rainfall. Note that recommended PSD values that are lower than the computed PSDs were used for statistical tests and that explains why there is no statistical difference between the PSDs for dry weather and light rainfall at site 2 .

\section{Conclusion}

Based on the synthesis of empirical evidences from the rainfall impact study carried out at single carriageway roads in Skudai town, Malaysia, the paper has shown that rainfall has significant effect on sight distances, hence it can be concluded that; gap times can be substituted for the generalised reaction time of $2 \mathrm{~s}$ or $2.5 \mathrm{~s}$ because they are indicative of drivers response time envelope. Furthermore, heavy rainfall can be called upon to account for the largest SSD and PSD reductions at all sites. Finally, the hypothesis that rainfall irrespective of intensity would reduce SSD and PSD significantly is valid.

\section{Acknowledgements}

The authors wish to acknowledge with thanks the Dungun Traffic Police and Public Work Department for ensuring safety of crews during the installation of data collection equipment, Department of Irrigation and Drainage of Malaysia for providing the rainfall data and also Road Safety Research Group of Universiti Teknologi Malaysia. 


\section{References}

Alhassan, H.; Ben-Edigbe, J. 2011. Effect of Rainfall Intensity Variability on Highway Capacity Loss, European Journal of Scientific Research, 49(1): 18-27.

Ben-Edigbe, J.; Ferguson, N. 2005. The Extent of Roadway Capacity Shift Resulting from Pavement Distress. In Proceedings of the Institution of Civil Engineering, Transport, 158(4): 27-32.

Gurupackiam, S.; Lee Jones Jr, S. 2012. Empirical Study of Accepted Gap and lane Change Duration within Arterial Traffic Under Recurrent and Non-Recurrent Congestion, International Journal for Traffic and Transport Engineering. DOI: http://dx.doi.org/10.7708/ijtte.2012.2(4).02,2(4): 306-322.

Hogema, J.H. 1996. Effects of Rain on Daily Traffic Volume and on Driving Behavior. TNO report TM-96-B019, Human Factors Research Institute, Soesterberg, Netherlands. 14 p.

Keay, K.; Simmonds, I. 2005. The Association of Rainfall and Other Weather Variables with Road Traffic Volume in Melbourne, Australia, Journal of Accident Analysis and Prevention. DOI: http://dx.doi.org/10.1016/j. aap.2004.07.005, 37(1): 109-124.
Malaysia Highway Capacity Manual (MHCM). 2011. Public Works Planning Department, Ministry of Works, Malaysia. 178 p.

Minderhoud, M.M.; Botma, H.; Bovy, P.H.L. 1997. Assessment of Roadway Capacity Estimation Methods,_Transportation Research Record: Journal of the Transportation Research Board. DOI: http://dx.doi. org/10.3141/1572-08, 1572: 59-67.

Mohan Rao, A.; Ramachandra Rao, K. 2012. Measuring Urban Traffic Congestion-A Review, International Journal for Traffic and Transport Engineering. DOI: http://dx.doi. org/10.7708/ijtte.2012.2(4).01, 2(4): 286-305.

Yeon, J.; Hernandez, S.; Elefteriadou, L. 2009. Differences in freeway capacity by day of the week, time of day and segment type, Journal of Transportation Engineering. DOI: http://dx.doi.org/10.1061/(ASCE)0733947X(2009)135:7(416), 135(7): 416-426. 